\title{
OS PRINCÍPIOS DA TEORIA DAS NECESSIDADES HUMANAS BÁSICAS E SUA APLICABILIDADE PARA O PACIENTE COM INDICAÇÃO DE TRANSPLANTE DE CÓRNEA*
}

\author{
Lorita Marlene Freitag Pagliuca**
}

\begin{abstract}
RESUMO: A Teoria das Necessidades Humanas Básicas de Wanda Aguiar Horta propõe cinco princípios. Os testes para comprovação da aplicabilidade de teorias devem compreender estudos que experimentem a base conceitual com diferentes clientelas. Selecionou-se como tal, pacientes com indicação de transplante de córnea, em que se identificaram como necessidades básicas afetadas as de vida gregária, segurança, aprendizagem, recreação e lazer, auto-imagem, auto-realização, filosofia de vida e sexualidade. A intervenção de enfermagem proposta foi analisada à luz dos princípios da teoria, centralizando-se no de que "todo cuidado de enfermagem é preventivo, curativo e de reabilitação" demonstrando, ainda, que os princípios guardam estreita relação entre si.
\end{abstract}

\begin{abstract}
The Theory of Human Basic Needs by Wanda Aguiar Horta suggests five principles. The tests conceived in order to certify the applicability of theories should include studies which will try out the conceptual basis in different cases. Bearing this in mind, patients indicated for cornea transplantation were chosen, whose basic needs involved were the gregarious life, security, apprenticeship, leisure, self-image, selfachievement, philosophy and sexuality. The proposed nursery intervention was analyzed under the theory principles, concentrating on the one that states "every nursing care is preventive, curative and implies rehabilitation", demonstrating also that the principles are closely related to each other
\end{abstract}

\section{INTRODUÇÃO}

Os testes para comprovação de teorias de enfermagem podem atender a diferentes finalidades: explorar a utilidade da teoria via pesquisas para avaliar a aplicabilidade na prática, ensino e administração; comprovação de propostas ou teorias de outras disciplinas para o emprego pela enfermagem de teorias desenvolvidas em outras áreas; comprovação dos conceitos de enfermagem pelo desenvolvimento de instrumentos, ferramentas e significados válidos e razoáveis para se comprovar ou não, se os conceitos são aplicáveis à enfermagem; comprovação das propostas de enfermagem derivadas de teorias de enfermagem que MELEIS ${ }^{(5)}$ coloca como propostas existenciais que relacionam dois ou mais conceitos para demonstrar a existência deles; propostas previsoras para demonstrar o efeito de um conceito sobre outro e propostas prescritivas para testar as intervenções da enfermagem para obter os objetivos desejados.

A teoria das Necessidades Humanas Básicas de HORTA $^{(3)}$ apresenta uma proposta para a enfermagem com a colocação de filosofia, proposições, conceitos, definições e princípios. Os testes de teorias devem validar ou refutar estas propostas, o que pode ser feito progressivamente com cada um de seus componentes. Segundo SOUZA, GUTIERREZ e CASTRO $^{(8)}$ "um princípio é uma premissa chave ou suposição básica que é essencial para expor ou explicar uma teoria".

Os conceitos são abstratos e gerais; as proposições derivam dos conceitos e expressam uma verdade fundamental a seguir; os princípios são enunciados, admitidos provisoriamente como inquestionáveis, mas que se prestam ao teste, à experimentação.

* Prêmio Wanda Aguiar Horta - $2^{\circ}$ lugar - 44 Congresso Brasileiro de Enfermagem, Brasília, DF, 4 a 9 de outubro de 1992.

** Professora Titular de Enfermagem Fundamental do Departamento de Enfermagem da Universidade Federal do Ceará - UFC 
HORTA $^{(3)}$ estabelece os seguintes princípios: a enfermagem respeita e mantém a unicidade, autenticidade e individualidade do ser humano; a enfermagem é prestada ao ser humano e não à sua doença ou desequilíbrio; todo cuidado de enfermagem é preventivo, curativo e de reabilitação; a enfermagem reconhece o ser humano como membro de uma família e uma comunidade; a enfermagem reconhece o ser humano como elemento participante ativo no seu autocuidado"

A escolha da clientela para estudo, o paciente com indicação de transplante de córnea, prende-se ao reconhecimento da importância da visão, responsável por $80 \%$ das informações perceptivas das pessoas, e das projeções da Organização Mundial da Saúde que estima em 500/100.000 habitantes afetados pela cegueira. As pessoas com indicação de transplante de córnea encontram-se numa situação ambígua pois, ao mesmo tempo, tem a perspectiva da cura pelo transplante, mas sofrem longo período de espera pela falta de estrutura dos serviços de saúde e despreparo da sociedade para tratar das doações de órgãos.

A enfermagem, enquanto profissão, não tem tido um papel definido com esta clientela e acredita-se poder demonstrar a atuação da enfermeira em um campo novo com significativa expansão de papeis.

São objetivos deste estudo:

1. Aplicar a consulta de enfermagem a pacientes com indicação de transplante de córnea.

2. Testar os princípios da teoria das necessidades humanas básicas ao paciente com indicação de transplante de córnea.

\section{METODOLOGIA}

O universo deste estudo é composto por pacientes com indicação de transplante de córnea, inscritos no Banco de Olhos de uma instituição filantrópica, na cidade de Fortaleza, no período de agosto de 1990 a junho de 1991.

A experiência acumulada no contato com este tipo de clientela permitiu caracterizar dois grupos: os que se beneficiam do transplante e, aparentemente, retornam à vida anterior ao problema visual, e os que não realizam o transplante e, conseqüentemente, têm suas vidas transformadas pela deficiência visual que persiste.

A amostra selecionada constitui-se em dois pacientes com indicação de transplante de córnea, acompanhados de março a junho de 1991; a escolha recaiu sobre estes dois pacientes por caracterizarem: um, o grupo de sucesso e o outro, o grupo de insucesso.

A coleta de dados foi realizada com o emprego da consulta de enfermagem compreendendo histórico, prescrição e evolução de enfermagem, fundamentada na teoria das necessidades humanas básicas.

Respeitando-se a natureza da realidade que se deseja estudar, optou-se pela pesquisa qualitativa e, dentro desta, o método de estudo de caso. As características fundamentais do estudo de caso apontadas por LÜDKE e ANDRÉ( ${ }^{(4)}$ são: os estudos de caso visam à descoberta, enfatizam a interpretação em contexto, buscam retratar a realidade de forma completa e profunda, usam uma variedade de fontes de informação, revelam experiências de vida e permitem generalizações naturalísticas, procuram representar os diferentes e às vezes conflitantes pontos de vista presentes numa situação social e utilizam uma linguagem e uma forma mais acessível do que outros relatórios de pesquisa.

Para testar os princípios da teoria das necessidades humanas básicas, estes serão analisados frente aos problemas identificados, à prescrição e evolução de enfermagem implementadas nos pacientes em estudo, considerando os níveis de promoção das intervenções de enfermagem.

\section{APRESENTAÇÃO E ANÁLISE DOS ESTUDOS DE CASO}

\section{Estudo de Caso 1: \\ Histórico de Enfermagem - \\ Pré-transplante de Córnea}

\section{I - Identificação \\ Nome: João \\ $\mathrm{N}^{\circ}$ registro: ---}

Idade: 28 anos

Sexo: masculino

Grau de instrução: $3^{\mathrm{a}}$ série do $1^{\circ}$ grau

Diagnóstico médico: catarata congênita; complicação de íris e córnea; cinco cirurgias oftálmicas anteriores.

Data de indicação para transplante: há 8 anos

Informante: mãe

\section{II - Necessidades Humanas Básicas}

1. Gregária: tem seis irmãos, reside com mãe (viúva) e quatro irmãos; relaciona-se mal com os irmãos. Não se 
relaciona com outros grupos, sente-se rejeitado. Casa própria com saneamento básico, renda familiar pequena mas garante a subsistência. Sua mãe lhe destina a aposentadoria do pai.

2. Segurança:

locomove-se independentemente no domicílio, mas fora de casa necessita de ajuda. Manifesta comportamento desajustado, alcoólatra com crises de agressividade, cria dificuldades em casa. Teve paralisia infantil com 1 ano de idade, ficando com leve deficiência motora. Os problemas visuais iniciaram-se aos 8 anos de idade; sofreu vários tratamentos, era cooperativo na infância mas na adolescência revoltou-se e não quis mais se tratar, nega qualquer tratamento, inclusive transplante.

3. Aprendizagem:

tem conhecimento da sua deficiência e da indicação do transplante. Refere que foi chamado uma vez para transplante e lhe disseram que "não dava"; desde então seu comportamento social desintegrou-se. Desinteressou-se pelos estudos devido à deficiência visual.

4. Recreação e Lazer:

gosta de tocar violão e cantar; passa horas nessas atividades; não gosta de grupos sociais.

5. Auto-imagem: comprometida; considera-se feio e segregado pelos defeitos físicos (paralisia + deficiência visual).

6. Auto-realização:

comprometida; não se identificam objetivos pessoais que indiquem um projeto de vida. Usa suas limitações físicas como impeditivas para a autorealização, mas percebe-se que as limitações são de fundo emocional.

7. Filosofia de vida: não foi possível identificar satisfatoriamente; considera-se feio e segregado.

8. Sexualidade:

gostaria de namorar, mas as garotas não se interessam por ele, por ser feio; o preconceito ao deficiente físico é percebido quando as garotas olham com pena ou rejeitam uma tentativa de flerte.

Observação:

sendo informante a mãe do paciente (ele recusouse a comparecer à consulta), interrompemos aqui a coleta de dados do Histórico de Enfermagem.

\section{III - Impressões do Entrevistador:}

Conforme registro do paciente, inscrito há 8 anos para transplante, foi chamado para realizar o transplante várias vezes (há 4 registros) e não compareceu. Em contato telefônico, solicitamos o comparecimento do paciente para esta consulta. Como ele se negou, pedimos à mãe para comparecer. Durante a realização da entrevista, percebe-se que a mãe gosta muito do filho, diz ser a única pessoa que gosta dele, tem medo de morrer e ninguém cuidar dele. Acredita que errou na educação do filho, pois sempre o superprotegeu e quando chegou à idade adulta não estava preparado para conviver com o mundo, com sua deficiência física. Relata que agora o filho não quer mais vir à Instituição com medo de ter nova esperança e não voltar a enxergar; não há registro explicando porque o primeiro transplante não pôde ser realizado e se ainda há indicação de transplante. Ao termino da entrevista, visitamos as dependências da Instituição para mostrar as possibilidades de reabilitação ainda que persista a deficiência visual. Teve a oportunidade de conversar com professores e alunos e disse que fará o possível para o filho vir para cá.

\section{IV - Prescrição de Enfermagem:}

1. Orientar quanto à necessidade de consulta oftalmológica.

2. Convidar para visitar o Instituto.

3. Estimular convivência com outros deficientes visuais.

\section{V - Observação:}

Prescrição dada à mãe do paciente, visto que este não compareceu à consulta.

VI - Evolução de Enfermagem:

Tentamos inúmeros contatos telefônicos, todos infrutíferos; o inscrito nega-se a nos atender e comparecer à Instituição para exame oftalmológico ou programa de reabilitação. Decidiu-se não mais abordá-lo pois, segundo informação da mãe, fica deprimido e revoltado com cada nova chamada. Continua inscrito no Banco de Olhos. 


\section{Estudo de Caso 2:}

Histórico de Enfermagem -

Pré-transplante de Córnea

I - Identificação

Nome: Pedro

$\mathrm{N}^{\circ}$ do registro: 4

Idade: 14 anos

Sexo: masculino

Grau de instrução: excepcional

Diagnóstico médico: ceratocone + úlcera O.D.; perda total do O.E. mesma causa

Data indicação para transplante: $1^{\mathrm{a}}$ indicação abril/90, em junho/90 perdeu O.E.; $2^{\mathrm{a}}$ indicação. há 3 dias - urgência.

Informante: a mãe

\section{II - Necessidades Humanas Básicas}

1. Gregária:

família composta pelos pais e quatro filhos deles $(19,17,14,10$ anos). Bom relacionamento familiar, acompanhado dos pais que demonstram muito afeto. Casa com instalação hidro-sanitária, conjuntos do PROAFA; o pai é guarda marítimo; a mãe deixou de trabalhar para se dedicar ao filho. Apesar de dificuldades, a família provê adequadamente suas despesas.

2. Segurança:

física - habitação com as condições satisfatórias de segurança; não há objetos ou móveis que possam feri-lo. Psíquica - avaliação dificultada pela excepcionalidade do jovem; comunicação canalizada pela mãe; reage ás solicitações com sorrisos, expressão verbal restrita. Social - aparentemente a excepcionalidade é o mais forte impeditivo para o relacionamento social; no momento o O.D. ocluso para evitar evisceração; em casa tem se restringido ao leito.

3. Aprendizagem:

freqüenta escola de excepcionais; tem dificuldade para compreender sua situação atual de saúde; retraído após curativo oclusivo. No momento não está freqüentando a escola. Família ciente da gravidade da situação do paciente (indicação de urgência para transplante); pode perder o $2^{\circ}$ olho em poucos dias. A mãe não sabe informar a situação vacinal do jovem; tem cartão de vacinação em casa e irá consultar.

4. Recreação e Lazer: anteriormente participativo em atividades de grupo de escola e família, atualmente retraído; gosta de TV e como não está enxergando, tem atualmente longos períodos de silêncio.

5. Auto-imagem:

sem condições adequadas de avaliação; a mãe relata que ele gosta de se sentir amimado; roupas adequadas para a ocasião, bem penteado, cores combinando. Apresenta incoordenação motora de membros superiores, membros inferiores de difícil avaliação pela oclusão ocular: fácies típica de excepcional.

6. Auto-realização:

considerando suas limitações físicas e intelectuais, o jovem aparenta ser realizado anteriormente ao agravamento do problema visual. Não dispomos de critérios confiáveis para fazer esta avaliação. Percebe-se que era feliz e integrado no sue ambiente de convívio.

7. Filosofia de vida:

não abordamos este aspecto quanto ao jovem, mas a informante, sua mãe, manifesta filosofia de vida de valores simples mas consistente. Aceita com naturalidade a excepcionalidade do filho, mas demonstra muita preocupação pelo sofrimento que poderia ter se ficasse cego.

8. Sexualidade:

a mãe fala com naturalidade do surgimento dos caracteres sexuais próprios da idade; diz que seu filho lhe mostra e acha engraçado; não mencionou detalhes de interesse sexual da parte do seu filho ou comportamento não aceitos pelo grupo social.

\section{II - Impressão do Entrevistador:}

Informante esclarecida e cooperativa, relatou que em abril/90 consultou oftalmologista sobre o problema do O.E. Foi informado pelo especialista que corria o risco de perder o olho e ficou com muita raiva pela forma como foi dito; procurou outro especialista que afirmou que o caso não era tão sério e dois meses depois o jovem perdeu o olho. Hoje está muito preocupada que aconteça o mesmo com a outra vista e deseja evitar que isto aconteça.

\section{III - Prescrição de Enfermagem}

1. Encaminhar para exames pré-operatórios.

2. Orientar a família para participar da busca da 
córnea.

3. Estimular ao convívio social através da participação nos diálogos.

4. Estimular a família a manifestar seus sentimentos.

IV - Evolução de Enfermagem

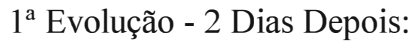

Colaborando na busca de doação de córnea, tem comparecido diariamente á emergência do hospital. Vivenciamos em conjunto a abordagem a parentes de pessoas em óbito recente para conseguir doação. Chorou muito com uma mãe que teve sua filha morta em atropelamento; a mãe negou a doação, disse que não pensava ser tão difícil falar com a família. Tivemos ajuda da assistente social. Exames pré-operatórios prontos.

\section{$2^{\mathrm{a}}$ Evolução - 4 Dias Depois:}

Houve um óbito de recém-nato de uma prima da mãe do jovem; após muito esforço conseguiu e obteve a doação das córneas do neném. Não foi possível aproveitar a doação, o tamanho das córneas era insuficiente.

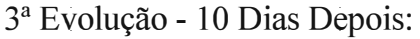

Obtida a doação na emergência, realizado transplante sem anormalidades. Na alta hospitalar, olho direito ocluso. Orientada pelo cirurgião para manter tampão. Não acompanhamos a cirurgia.

\section{$4^{a}$ Evolução - 20 Dias Depois:}

Continua com olho direito ocluso, jovem tenta coçar o olho; a mãe relata que já enxerga; procura assistir à televisão, levantando os curativos. Compareceu à reunião mensal, fez seu relato de experiência, explicou que o caso de seu filho era de urgência e por isto foi operado logo; contou como foi difícil falar com pessoas que perderam entes queridos para tentar a doação; ainda assim, acha que valeu a pena o esforço. Solicitou declaração para justificar as faltas do filho no colégio. Pai presente.

\section{Evolução:}

Sem curativo oclusivo, visão recuperada, jovem continua reticente para conversar conosco; aparenta alegria, acompanhado dos pais.

\subsection{Análise dos dados}

Os dois pacientes selecionados para estudo de caso são do sexo masculino, um com 14 e outro com 28 anos de idade. O mais velho tem a terceira série do primeiro grau, o mais jovem é excepcional.

A indicação de transplante do paciente mais velho, que passamos a chamar de João, foi feita há 8 anos. Pedro teve uma indicação de urgência há três dias de nosso primeiro contato. João tem antigos problemas oftalmológicos, sendo que o diagnóstico médico é impreciso. Pedro apresentou um ceratocone acompanhado de úlcera no olho direito.

Infelizmente nada mais se sabe do diagnóstico de João. Tentemos entender o de Pedro.

As doenças de córnea são genericamente denominadas distrofias corneanas, têm caráter hereditário, podendo ser autosômicas dominantes ou recessivas ligadas ao sexo; algumas não têm hereditariedade.

São classificadas topograficamente de acordo com a camada corneana acometida; as distrofias superficiais comprometem o epitelio e a membrana de Bowman; as distrofias profundas atingem o estroma corneano ou as membranas posteriores - membrana Decemet e endotélio.

As distrofias corneanas apresentam uma variação muito extensa de manifestações com lesões características, mas se pode tentar resumir seu quadro da seguinte forma: as lesões transformam-se em cicatrizes opacas, gerando a deficiência visual. Para a correção desta situação indica-se a ceratoplastia.

Dentre as distrofias destaca-se o ceratocone, que é uma distrofia do tipo ectática - dilatação de órgão oco.

O ceratocone, segundo ROCHA ${ }^{(7)}$, é o mais comum no nosso meio. Caracteriza-se pela deformação cónica da córnea, instalando-se preferencialmente na puberdade. Evoluindo o ceratocone, a córnea mais se adelgaça e afunila, desenvolvendo opacidades apicais. Somam-se a essas, alterações de forma, curvatura e transparência, acarretando profunda deficiência visual.

Quando a terapêutica não é instituída em tempo hábil, pode-se fazer presente a úlcera de córnea, devido ao adelgaçamento. Há o risco de perda de substância com danos irreparáveis para a visão.

A descrição sumária da patologia que acometeu Pedro foi aqui colocada para se classificar a gravidade do caso e a pertinência da rotulação URGENTE.

O próximo aspecto a ser analisado refere-se ao informante, que nos dois estudos de caso seleciona- 
dos, foram representados pela mãe, ainda que por circunstâncias totalmente adversas entre si.

João recusou-se a atender o chamado do Banco de Olhos, sendo substituído por sua mãe; Pedro é excepcional, portanto, dependente e sem condições de fornecer as informações necessárias.

Ainda que João e Pedro não representem todas as variáveis dos pacientes com indicação de transplante de córnea, pode-se afirmar que, na maioria absoluta dos casos, o paciente não tem condições de se locomover sozinho para o Banco de Olhos, necessitando do auxílio da família ou de amigos.

GRAÇAS $^{(2)}$ citando MORRISEY, afirma que a educação da família deve ser parte integrante do processo de reabilitação, uma vez que o objetivo principal do trabalho com o cliente visa a sua preparação para viver na comunidade. Assim sendo, todo contato com os membros da família deve ser convertido numa situação de aprendizagem da qual se deve tirar o máximo proveito em cada oportunidade. A eles devem ser ensinados os princípios básicos de saúde e as atividades de reabilitação a serem desenvolvidas com o cliente. A família também deve ser ajudada a fim de que possa compreender e aceitar as limitações do cliente, entretanto, deve ser advertida quanto aos prejuízos que uma superproteção pode causar ao processo de independência da pessoa deficiente.

As famílias de João e Pedro agiram de maneira diametralmente opostas quanto à situação de conviver com um deficiente visual. As situações são diferentes entre si. Enquanto João teve um problema visual de longa duração, mais de oito anos, sua personalidade foi se modificando e a estrutura familiar também. Pedro passou por um problema de saúde agudo, severo, mas com resolutividade rápida e satisfatória.

Quando um membro da família apresenta um problema de saúde, sabe-se que a família como um todo é afetada. Mecanismos de adaptação se criam para proteger a estrutura familiar e do membro afetado diretamente. Quando os problemas se exacerbam a família pode se tornar incapaz de, sozinha, buscar alternativas de adaptação, podendo, então, rejeitar a pessoa que passa a ser o próprio problema.

A necessidade básica gregária de João estava afetada. Das pessoas que compunham o núcleo familiar, apenas sua mãe ainda mantinha vínculos afetivos, apesar de questionável a ajuda efetiva que estes vínculos podem trazer para o paciente. Ela se percebe como a única pessoa que ama e teme lhe faltar; sua postura excessivamente protetora dificultou, ou im- pediu, que o paciente se auto-desenvolvesse.

A cronicidade da deficiencia visual de João tornou-o cada vez mais isolado dos grupos sociais e da família. Quando a situação-problema se torna crônica, trazendo mudanças estruturais mais duradouras, há um enfraquecimento dos laços afetivos e há a tendência a uma acomodação dos membros da família.

Este pensamento é reforçado pela atitude da família de Pedro, um problema agudo, que mobilizou todos os esforços da família para solucioná-lo. Percebeu-se que o acompanhamento familiar adotado manteve-os unidos e a estrutura interna íntegra. Vale ressaltar que esta família estava habituada a conviver com um deficiente mental, o que pode ter criado mecanismos adequados de auto-ajuda.

A participação ativa da família em todas as etapas de vida de um deficiente visual é inquestionável para sua cura ou reabilitação. Em nossa experiencia lembramos um senhor, de boa condição sócio-econômico-cultural, com 74 anos de idade, residente em outra cidade, com a filha morando na capital, que foi chamado seis vezes para transplante e não compareceu porque a filha sempre tinha um impedimento pessoal. Na consulta de enfermagem, após inúmeras datas agendadas, em que finalmente o paciente foi trazido pela filha, ele emocionou-se ás lágrimas por saber que estava próximo o dia do transplante. Escondemos dele a realidade: já poderia ter sido transplantado há mais de ano.

As reações das pessoas que se tornam deficientes físicas diferem muito de umas para outras e não se pode falar em uma "personalidade do deficiente". FIGUEIREDO ${ }^{(1)}$ lembra a negação, que pode ser interpretada como o modo de o indivíduo se proteger inconscientemente de um choque demasiadamente brusco, e isto tem sido constatado nos casos em que a deficiência é adquirida de súbito. Ansiedade e depressão ocorrem freqüentemente como reações à perda do eu e de algumas aptidões anteriores; ou a regressão: quando o deficiente age como alguém mais jovem, tornando-se, talvez, superdependente; aumento de isolamento: eliminação de contato com outras pessoas; crescente uso da fantasia: projeção de novas identificações.

\section{APLICABILIDADE DOS PRINCÍPIOS DA TEORIA DAS NECESSIDADES HUMANAS BÁSICAS}

Os conceitos são abstratos e gerais; as proposições derivam dos conceitos e expressam uma verdade fundamental a seguir; os princípios são enunciados, 


\section{Figura 1}

A enfermagem respeita e mantém a unicidade, autenticidade e individualidade do ser humano

A enfermagem é prestada ao ser humano e não à sua doença ou desequilíbrio.

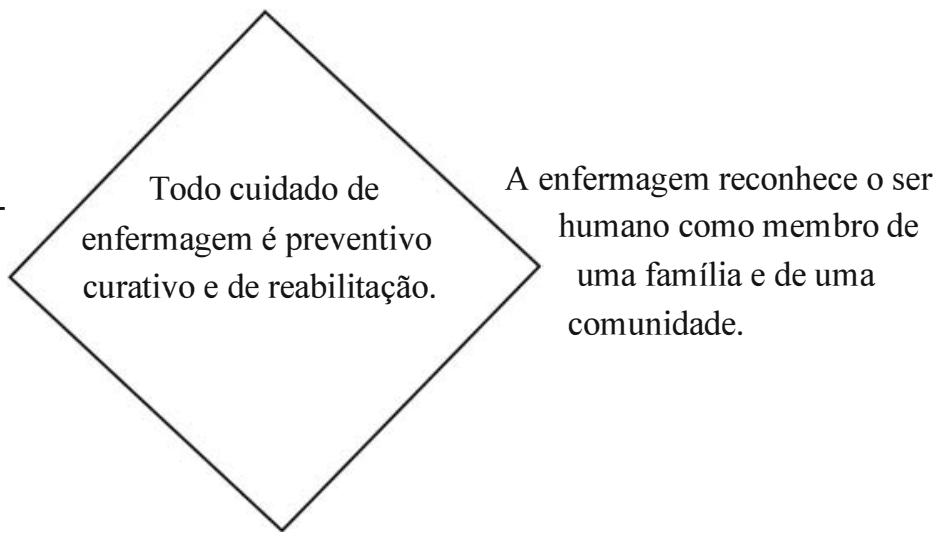

A enfermagem reconhece o ser humano como elemento participante ativo no seu autocuidado. admitidos provisoriamente como inquestionáveis, mas que se prestam ao teste, à experimentação. HOR$\mathrm{TA}^{(3)}$ estabelece os seguintes princípios:

- "a enfermagem respeita e mantém a unicidade, autenticidade e individualidade do ser humano;

- a enfermagem é prestada ao ser humano e não à sua doença ou desequilíbrio;

- todo o cuidado de enfermagem é preventivo, curativo e de reabilitação;

- a enfermagem reconhece o ser humano como membro de uma família e uma comunidade;

- a enfermagem reconhece o ser humano como elemento participante ativo no seu autocuidado."

É proposta deste estudo analisar a aplicabilidade dos princípios da Teoria das Necessidades Humanas Básicas, de Wanda HORTA, para pacientes com indicação de transplante de córnea.

Após reflexão sobre o conteúdo de cada princípio, suas interrelações com o conceito de enfermagem e o que se acredita adequado para a clientela, propõese o seguinte modelo de análise:

O esquema apresentado na figura 1 privilegia o princípio de que "todo o cuidado de enfermagem é preventivo, curativo e de reabilitação" e os outros quatro princípios sustentam, fundamentam e direcionam o que para nós é a essência da profissão: o "cuidado de enfermagem".

As recomendações do I Seminário Nacional sobre o Perfil e Competência do Enfermeiro ${ }^{(6)}$ afirmam que, o cuidar tem sido a característica fundamental da profissão, e permeia todos os modelos teóricos existentes. Reforçam também a necessidade de reorientar as investigações científicas na área de enfermagem, para que se produzam conhecimentos específicos sobre a característica do CUIDAR em Enfermagem.

\section{Análise do Princípio:}

A enfermagem respeita e mantém a unicidade autenticidade e a individualidade do ser humano.

O problema central e primeiro - o comprometi mento da visão - caracteriza os dois pacientes selecionados para estudo de caso, formando uma unicidade com os demais problemas que afetaram as necessidades básicas psicossociais e psicoespirituais.

Os indivíduos são percebidos e tratados com uma situação tal em que as manifestações dos problemas de enfermagem guardam uma feição única, autêntica e individual de cada ser.

Enquanto João manifesta alterações na necessi- 


\section{Quadro I}

\section{Princípio: Todo cuidado de Enfermagem é preventivo, curativo e de reabilitação.}

PACIENTE: PEDRO

\begin{tabular}{|c|c|c|c|}
\hline CUIDADOS & & VEIS DE PROMOÇÃO & EVOLUÇÃO \\
\hline $\begin{array}{l}\text { 1. Encaminhar para exames } \\
\text { pré-operatórios. }\end{array}$ & $\begin{array}{l}\text { Prevenção } \\
\text { Cura } \\
\text { Reabilitação }\end{array}$ & $\begin{array}{l}\text { - Evitar complicações trans e pós - Trans } \\
\text { operatórias. } \\
\text { - Permitir a realização do transplante. } \\
\text { - Recuperar a visão no pós- } \\
\text { transplante. }\end{array}$ & $\begin{array}{l}\text { - Trans e pós-operatórios sem } \\
\text { intercorrências. } \\
\text { - Transplante realizado em tempo } \\
\text { hábil. } \\
\text { - Visão recuperada. }\end{array}$ \\
\hline $\begin{array}{l}\text { 2. Orientar a família para participar } \\
\text { na busca de córnea. }\end{array}$ & $\begin{array}{l}\text { Prevenção } \\
\text { Cura } \\
\text { Reabilitação }\end{array}$ & $\begin{array}{l}\text { - Diminuir o tempo de espera para } \\
\text { transplante. } \\
\text { - Realizar o transplante. } \\
\text { - Recuperar a visão. }\end{array}$ & $\begin{array}{l}\text { - Transplante realizado em tempo } \\
\text { hábil. } \\
\text { - Transplante realizado } \\
\text { - Visão recuperada. }\end{array}$ \\
\hline $\begin{array}{l}\text { 3. Estimular ao convívio social através } \\
\text { da participação nos diálogos. }\end{array}$ & $\begin{array}{l}\text { Prevenção } \\
\text { Cura } \\
\text { Reabilitação }\end{array}$ & $\begin{array}{l}\text { - Evitar isolamento social. } \\
\text { - Perceber que o seu problema não é } \\
\text { único. } \\
\text { - Manter vida social ativa integrada } \\
\text { com grupos específicos. }\end{array}$ & $\begin{array}{l}\text { - Participação durante todo o processo } \\
\text { pré-trans-pós-transplante. } \\
\text { - Em reunião mensal do grupo, teve } \\
\text { facilidade para se expressar. } \\
\text { - Participativo com a equipe de } \\
\text { saúde, grupo de parentes e grupo } \\
\text { escolar. }\end{array}$ \\
\hline $\begin{array}{l}\text { 4. Estimular a família a manifestar } \\
\text { seus sentimentos. }\end{array}$ & $\begin{array}{l}\text { Prevenção } \\
\text { Cura } \\
\text { Reabilitação }\end{array}$ & $\begin{array}{l}\text { - Permitir que se identifiquem } \\
\text { conflitos p/ intervenção adequada. } \\
\text { - Perceber que seus sentimentos são } \\
\text { - Proporcionar condições para vida } \\
\text { familiar e comunitária adaptada. }\end{array}$ & $\begin{array}{l}\text { - Comentavam seus medos e } \\
\text { expectativas. } \\
\text { - Sentimentos de depressão e raiva } \\
\text { manifestos aceitavelmente. } \\
\text { - Vida familiar manteve-se íntegra, } \\
\text { apesar da problemática de Pedro. }\end{array}$ \\
\hline
\end{tabular}

dade gregária, com franca rejeição de seus irmãos e outros grupos sociais, Pedro é aceito, amado e amparado por todos que o rodeiam.

O comprometimento da segurança, aprendizagem, auto-imagem, auto-realização, sexualidade e filosofia de vida - são contundentes na sua forma de apresentação por João. Quando se passa a compreender Pedro, constata-se que, neste, a necessidade de recreação e lazer foi a mais comprometida.

As diferenças de circunstâncias que geraram estas histórias de vida são respeitadas na coleta de dados, através do Histórico de Enfermagem, permitindo a análise circunstancial de sua manifestação, e que, as ações de enfermagem, os CUIDADOS fossem dirigidos a cada ser humano, respeitando-se suas características individuais.

Além de o Histórico de Enfermagem se constituir num instrumento estruturado, orientado para a coleta de informações pré-determinadas, permite também que se obtenha o registro da problemática pessoal.

O tipo de intervenção de enfermagem, ou CUIDA-
DO, não se caracterizou por prescrições-padrão, visto que se procurou respeitar o enunciado do princípio.

Com Pedro os cuidados de enfermagem foram executados integralmente; com João, tal não ocorreu. João recusou-se a comparecer à instituição; talvez aí esteja, na sua forma plena, respeitando o princípio proposto, visto que na sua autenticidade e liberdade, João recusou o cuidado oferecido.

\section{Análise do Princípio:}

A enfermagem é prestada ao ser humano e não à sua doença ou desequilíbrio.

O levantamento das necessidades humanas básicas afetadas não se centralizaram no diagnóstico clínico, tanto que João não tinha diagnóstico definitivo, e não inviabilizou a aplicação do Histórico de Enfermagem. Pedro, com diagnóstico clínico esclarecido, ainda assim, tinha necessidades básicas comprometidas.

A falta de prioridade conferida à doença, ou desequilíbrio, abre espaço para uma ação mais eficaz 


\section{Quadro II}

Princípio: Todo cuidado de Enfermagem é preventivo, curativo e de reabilitação.

\begin{tabular}{|c|c|c|c|}
\hline CUIDADOS & & VEIS DE PROMOÇÃO & EVOLUÇÃO \\
\hline $\begin{array}{l}\text { 1. Orientar quanto à necessidade de } \\
\text { consulta oftalmológica. }\end{array}$ & $\begin{array}{l}\text { Prevenção } \\
\text { Cura } \\
\text { Reabilitação }\end{array}$ & $\begin{array}{l}\text { - Permitir o correto diagnóstico } \\
\text { médico para previnir uma perda } \\
\text { total da visão. } \\
\text { - Propor a intervenção médica } \\
\text { adequada (transplante?), tomando-o } \\
\text { cônseio de suas possibilidades de } \\
\text { cura ou de adaptação a uma possível } \\
\text { situação de cegueira permanente. } \\
\text { - Propor programa de reabilitação } \\
\text { condizente com necessidades } \\
\text { psicobiológicas, psicossociais e } \\
\text { psicoespirituais. }\end{array}$ & $\begin{array}{l}\text { - Paciente não aceitou a prescrição } \\
\text { dos cuidados; nega-se a manter } \\
\text { contato com pessoa da Instituição. }\end{array}$ \\
\hline 2. Convidar para visitar o Instituto. & $\begin{array}{l}\text { Prevenção } \\
\text { Cura } \\
\text { Reabilitação }\end{array}$ & $\begin{array}{l}\text { - Evitar desintegração severa e } \\
\text { irreversível da personalidade. } \\
\text { - Permitir a intervenção de equipe } \\
\text { multiprofíssional de saúde e } \\
\text { educação. } \\
\text { - Estimular programa de reabilitação } \\
\text { adequado. }\end{array}$ & \\
\hline $\begin{array}{l}\text { 3. Estimular convivência com outros } \\
\text { deficientes visuais. }\end{array}$ & $\begin{array}{l}\text { Prevenção } \\
\text { Cura } \\
\text { Reabilitação }\end{array}$ & $\begin{array}{l}\text { - Identificar suas potencialidades bio- } \\
\text { psico-sociais. } \\
\text { - Promover convívio interpessoal } \\
\text { agradável e gratificante. } \\
\text { - Estimular programa de reabilitação } \\
\text { adequado. }\end{array}$ & \\
\hline
\end{tabular}

da enfermeira, tanto no sentido de independência das ações de outros profissionais, como na de ajuda ao estabelecimento por parte do ser assistido, de uma reestruturação pessoal, a despeito de limitações decorrentes da doença.

\section{Análise do Princípio:}

A enfermagem reconhece o ser humano como membro de uma família e de uma comunidade.

Não existe o indivíduo sozinho. O homem, como ser social, acontece a partir da sua interação com seus pares. Daí acontece a formação de sua conduta, de sua auto-imagem, de sua identidade.

Os dois clientes foram abordados através da família; ainda que por circunstâncias próprias, foi desta que partiram as informações.

A família pode ser um elemento integrador, exemplo, a de Pedro, ou desintegrador como a de João. Em ambos os casos a enfermeira atua com o ser humano-familia.

Com a família de Pedro, participando espontânea e ativamente no tratamento proposto, os objetivos concretizaram-se em pouco tempo e com bons resultados.

João contou apenas com a ajuda de sua mãe, nem a sua própria ajuda aconteceu. Uma família complexa, desagregada, que o rejeita, mas acima de tudo, uma família. A proposta do CUIDAR, que na abordagem feita dirigiu-se especificamente ao cliente, deve ser revista para atingir a família.

A recusa de comparecer à instituição, por parte de João, e o estudo reflexivo sobre o princípio acima mencionado aponta, sem dúvida, para a intervenção familiar. É provável que para o paciente mudar seu comportamento, sem visualizar a perspectiva de um ganho, seja praticamente impossível e exigirá um dispêndio de energia muito grande. Se sua mãe fosse menos protetora e seus irmãos mais compreensivos poderia se abrir uma nova alternativa de recuperação.

A participação de Pedro e família no grupo comunitário dos pacientes que aguardam transplante, e o trabalho de mútua ajuda que se instalou entre seus elementos, confirmam que a enfermagem dirige-se para o ser humano, família e comunidade. 


\section{Análise do Princípio:}

A enfermagem reconhece o ser humano como elemento participante ativo no seu autocuidado.

O ser humano faz parte de um sistema familiar e social. E visto pela Teoria das Necessidades Humanas Básicas como um ser holístico, um todo, em interação com seu ambiente. Isto pressupõe assumir a responsabilidade por si mesmo em todos os aspectos da vida, inclusive a saúde.

A aceitação deste atributo do Homem cria modelos de enfermagem que procuram levar o indivíduo até o auto-cuidado, que está intimamente relacionado com o conceito de si mesmo.

Nos dois estudos de caso que empregamos para análise, temos um, o de Pedro, em que houve o assumir do auto-cuidado, enquanto no caso de João deixou de haver esta assunção de cuidado pessoal.

Ressalve-se que Pedro é um jovem excepcional. Portanto, não se pode esperar um assumir individual, mas como o ser humano é parte integrante de uma família, esta assumiu seu auto-cuidado frente á sua incapacidade.

O auto-cuidado, na situação de que se trata, compreendeu preparar os exames pré-operatórios, participar na busca de doação de córnea e do convívio social.

Crê-se não ser exagero afirmar que a negativa, por parte de João, em assumir seu auto-cuidado pode ser um motivo forte para não se obter um resultado satisfatório. Isto serve para reflexão da enfermagem quanto à importância para uma correta avaliação das capacidades do ser humano em assumir seu auto-cuidado e, inquestionavelmente, a urgência de se testar modelos para facilitar a implantação desta modalidade de assistência.

Confirmando-se, através da análise dos princípios, que a enfermagem respeita e mantém a unicidade, autenticidade e individualidade do ser humano; reconhece o ser humano como o membro de uma família e de uma comunidade; reconhece o ser humano como elemento participante ativo no seu auto-cuidado e que a enfermagem é prestada ao ser humano e não á sua doença ou desequilíbrio, buscou-se a análise dos CUIDADOS DE ENFERMAGEM prescritos para os dois pacientes, considerando-se, de fato, o cuidado de enfermagem como preventivo, curativo e de reabilitação.

A evolução de enfermagem - avaliação de cada cuidado prescrito - anotada ao lado da justificativa quanto ao nível de promoção: prevenção-cura-reabi- litação, permite visualizar se o objetivo da ação foi atingido, como pode ser observado nos quadros I e II.

Os resultados obtidos com Pedro são excelentes. Todas as prescrições de cuidados foram executadas e a evolução demonstra que se chegou â independência do cliente, neste caso independência associada à cura.

Fica evidenciado, no tipo de análise proposta, que os cuidados de enfermagem, obedecendo ao princípio selecionado como central, são de prevenção, cura e reabilitação.

Os princípios propostos pela Teoria das Necessidades Humanas Básicas são inter-relacionados: quando um não é respeitado, atingido, reflete seu resultado para os outros princípios.

João deixou de assumir seu auto-cuidado e sua mãe foi incapaz de assumi-lo. O princípio de que "a enfermagem reconhece o ser humano como elemento participante ativo no seu auto-cuidado" foi levado em conta na proposta de assistência de enfermagem mas, por falta de resposta adequada do paciente, não atingiu seus objetivos.

A resposta de João, de não participar de seu auto-cuidado, pode ter como origem a série de agressões à sua segurança, auto-imagem, auto-realização e filosofia de vida que foram se acumulando através dos anos.

Acredita-se no princípio de que o auto-cuidado é imprescindível para a execução do cuidar; a enfermagem deverá reinterpretar junto ao paciente e/ou sua família a participação destes no plano de assistência de enfermagem.

Fica registrada a problemática da recusa de par ticipação do paciente no auto-cuidado e a necessidade de enfermagem propor estratégias para assistir pessoas que assim se comportam.

\section{CONCLUSÕES}

Frentes aos objetivos traçados para este estudo, conclui-se que:

- a aplicação da consulta de enfermagem ao paciente com indicação de transplante de córnea permitiu identificar os problemas de enfermagem que afetam as necessidades de vida gregária, segurança, aprendizagem recreação e lazer, autoimagem, filosofia de vida e sexualidade como prioritárias para esta clientela. A intervenção de enfermagem foi viabilizada e expressa através dos cuidados na prescrição e constituíram-se em indi- 
cadores para a evolução de enfermagem;

- partindo-se da aceitação do conceito de enfermagem proposto por Wanda Horta, que traduz os princípios que norteiam sua teoria, e após a análise de cada um deles, pode-se concluir que, a intervenção de enfermagem baseada nas necessidades humanas básicas afetadas do ser humano, levam em conta cada um dos princípios e que estes centralizam-se no de que "todo cuidade de enfermagem é preventivo, curativo e de reabilitação", sendo que os cinco princípios propostos pela teoria guardam estreita relação entre si.

\section{REFERÊNCIAS BIBLIOGRÁFICAS}

1. FIGUEIREDO, Maria Cristina Soares. Contribuição do enfermeiro na reabilitação do paraplégico e seu ajustamento à vida domiciliar. Dissertação de mestrado - Escola de Enfermagem Ana Neri. Rio de Janeiro: 1981.

2. GRAÇAS, Elizabeth Mendes. O ensino e a prática da reabilitação motora e da comunicação verbal em hospitais gerais: estudo comparativo entre enfermeiras de ensino e serviço. Dissertação de mestrado - Escola de Enfermagem Ana Neri. Rio de Janeiro.

3. HORTA, Wanda de Aguiar. Processo de Enfermagem. São Paulo: EPU/EDUSP, 1979,99p.

4. LÜDKE, Menga, ANDRÉ, Marli E.D.A. Abordagens qualitativas de pesquisa: a pesquisa etnográfica e o estudo de caso. In: Pesquisa em educação: abordagens qualitativas. São Paulo: EPU, 1986, cap. 2, p. 11-44.
5. MELEIS, Afaf Ibrahim. Testes de teorias de enfermagem: processos conceituais e empíricos. In: Simpósio Brasileiro de Teorias de Enfermagem. Florianópolis, 1985. Anais . Florianópolis: Universidade Federal de Santa Catarina, 1985. p. 317-340.

6. RECOMENDAÇÕES. In: SEMINÁRIO NACIONAL SOBRE PERFIL E COMPETÊNCIA DO ENFERMEIRO, 1 ., 1987, Brasília, Anais ... Brasília: CNPq, 1987, p. 286-288.

7. ROCHA, Hilton Ensaio sobre a problemática da cegueira: prevenção-cura-reabilitação. Belo Horizonte: 1987, p. 156-169.

8. SOUZA, Mariana Fernandes de, GUITIERREZ, Maria Gaby Rivero de, CASTRO, Rosa Aparecida Pimenta de Análise da teoria das necessidades humanas básicas de Wanda de Aguiar Horta. In: SIMPÓSIO BRASILEIRO DE TEORIAS DE ENFERMAGEM, Florianópolis, 1985. Anais.. Florianópolis: Universidade Federal de Santa Catarina, 1985. p.209-230. 